\title{
Entre estilos y colectivo de pensamiento: genealogías y visión formativa de grupos de investigación en la historia de la educación matemática en Brasil
}

\begin{abstract}
Iran Abreu Mendes ${ }^{1}$
iamendes1@gmail.com

https://orcid.org/0000-0001-7910-1602

Carlos Aldemir Farias da Silva ${ }^{1}$

carlosfarias1@gmail.com

https://orcid.org/0000-0001-5463-1316

${ }^{1}$ Universidade Federal do Pará

Belém, Brasil

Recibido: 15/04/2020 Aceptado: 15/04/2020

Resumen

Este artículo presenta los resultados de una investigación que tuvo como objetivo discutir sobre las genealogías de grupos de investigación en la historia de la Educación Matemática en Brasil, desde la perspectiva de la visión formativa, los estilos y los colectivos de pensamiento, que caracterizaron el origen, la evolución y la difusión de las organizaciones sociales de estos grupos de investigación en sus generaciones descendientes, basados en el estudio de la epistemología de Ludwik Fleck, asociado con estudios sobre genealogía. Para llevar a cabo una investigación, llevamos a cabo una encuesta en el directorio del grupo de Investigación del CNPq, en la Plataforma Lattes y en otros archivos, con el fin de obtener información que ayude a caracterizar las epistemologías de los grupos en este campo de investigación, sus dimensiones de descendencia, desmembramiento y ramificaciones de miembros de cada grupo en forma de redes de conexiones entre investigadores, doctorados, sus respectivas líneas de investigación y producción generadas durante un curso de posgrado y después de su inclusión en el sistema de investigación en la historia de la educación matemática en brasil. A partir del levantamiento inicial no dirigido del CNPq, selecciones para analizar, grupos de grupos afectados Grupo-Pai, conforme como teorías adotadas para el estudio y aprofundamos una interpretación de información. Al final, identificamos una maduración académica de los procesos de capacitación de los investigadores hacia una constitución epistemológica para fortalecer el campo de investigación en la historia de la Educación Matemática y su ramificación multiplicativa en las diferentes regiones de Brasil. Sin embargo, también identificamos que las relaciones teóricoprácticas que emergen de esta capacitación en investigación aún no están bien establecidas en la capacitación de maestros que enseñan matemáticas y para la capacitación de maestros de investigación en la historia de la Educación Matemática en Brasil.
\end{abstract}

Palabras-clave: Investigación en Historia de la Educación Matemática. Historia de la Educación Matemática. Grupos de historia de la Educación Matemática. 


\title{
Entre estilos e coletivos de pensamento: genealogias e o ver formativo de grupos de pesquisa em História da Educação Matemática do Brasil
}

\begin{abstract}
Resumo
En este artículo se presentan los resultados de un estudio, basado en la epistemología de Ludwik Fleck y asociado con estudios sobre genealogía, que tuvo como objetivo discutir las genealogías de los grupos de investigación en Historia de la Educación Matemática de Brasil, desde la perspectiva de su visión formativa, y sus estilos y colectivos de pensamiento, con el fin de caracterizar el origen, la evolución y la difusión de las organizaciones sociales de estos grupos de investigación en relación con sus generaciones descendientes. En el inicio de la investigación, fueron revisados el Directorio de Grupos de Investigación del CNPq, la Plataforma Lattes y otros repositorios de pesquisa, con lo cual se obtuvo información que coadyuvó a la caracterización de las epistemologías, las dimensiones de descendencia, separaciones y ramificaciones de miembros de cada uno de los mencionados grupos de investigación, así como también a la identificación de las redes de conexión entre investigadores, estudiantes de doctorado, sus respectivas líneas de investigación y producciones generadas durante los estudios de posgrado y después de su inclusión en el sistema de investigación en la Historia de la Educación Matemática en Brasil. A partir del levantamiento inicial realizado en el Directorio del CNPq, se seleccionó para analizarlos a tres grupos que, de acuerdo con las teorías adoptadas para el estudio, fueron considerados Grupos-Padre, y se profundizó en la interpretación de la información. De ese modo, se consiguió identificar una trayectoria de maduración académica en los procesos de formación de los investigadores orientada hacia el fortalecimiento de la constitución epistemológica del campo de investigación en Historia de la Educación Matemática y su ramificación multiplicativa en las diferentes regiones de Brasil. Sin embargo, también identificamos que las relaciones teórico-prácticas que emergen de esa formación en investigación aún no están bien establecidas en la formación de los profesores que enseñan Matemática y tampoco en la formación de profesores-investigadores en Historia de la Educación Matemática en Brasil.
\end{abstract}

Palabras clave: Investigación en Historia de la Educación Matemática. Historia de la Educación Matemática. Grupos de Historia de la Educación Matemática.

\section{Between Styles and Collective of Thought: genealogies and formative view of Research Groups in the History of Mathematical Education in Brazil}

\begin{abstract}
This article presents the results of a research that aimed to discuss genealogies of research groups in History of Mathematical Education in Brazil, grounded in formative sight, styles and collectives of thought, which characterized social organizations' origin, evolution and dissemination of such research groups in their offspring generations, based on Ludwik Fleck's epistemology, associated with studies on genealogy. In order to operationalize this investigation, a survey in CNPq Research Groups Directory on Lattes Platform and in other files was carried out to obtain information that would contribute to characterizing groups' epistemologies in this investigative field, their descent dimensions, dismemberment and ramifications of members from each group, as well as in connection networks among researchers, doctoral graduate students, their respective research lines and productions generated during graduate school and after their inclusion in the research system on History of Mathematics Education in Brazil. Three groups considered as Parent Groups were selected for analysis in the initial survey in $\mathrm{CNPq}$
\end{abstract}


Directory, according to the theories adopted for this study, in order to deep the interpretation of information. In the end, an academic maturation of researchers' training processes was identified towards an epistemological constitution of strengthening the research field in History of Mathematical Education and its multiplicative ramification in Brazilian different regions. However, it was also identified that theoretical-practical relationships emerging from this research training are not yet well established in Math teachers' training. The same is true for research teachers' training in History of Mathematical Education in Brazil.

Keywords: Research in History of Mathematics Education. History of Mathematical Education. Groups on History of Mathematical Education.

\section{Considerações Preliminares}

Desde a penúltima década do século XX, os estudos e pesquisas sobre as relações entre História da Matemática e Educação Matemática vêm apresentando resultados centrados em enfoques nas histórias de vida e obra de matemáticos e educadores, bem como na formação de professores de Matemática, instituições escolares e nos processos de disciplinarização das matemáticas em nível de Educação Básica e ensino superior. Essas pesquisas quase sempre tomam como fundamentos princípios e procedimentos metodológicos o apelo à memória e a História Oral, materializados nas entrevistas e na organização da memória da Educação Matemática no Brasil. Além disso, a exploração de arquivos pessoais e de centros de documentação em todas as suas dimensões, bem como o método (auto)biográfico, têm ampliado as fontes das pesquisas em História da Educação Matemática e auxiliado os pesquisadores na busca de respostas acerca do processo de constituição dessa história plural, na qual a Educação Matemática vem se constituindo como uma área de produção de conhecimento, tanto na história das instituições como das disciplinas escolares e nas histórias de vida de professores de Matemática, protagonistas das histórias.

A partir de pesquisas que primeiramente tiveram como objetivo cartografar os processos de produção científica de História da Matemática, História para o Ensino da Matemática e História da Educação Matemática nos programas de pós-graduação stricto sensu do Brasil, das áreas de Educação, Educação Matemática, Ensino de Ciências Naturais e Matemática e áreas afins, entre 1990 e 2010, identificamos que, de um modo geral, as dissertações e teses estão organizadas em três subáreas: História e Epistemologia da Matemática (HepM); História para o Ensino da Matemática (HenM) e História da Educação Matemática (HedM) (cf. Mendes, 2010, 2012, 2018, 2019). Consequentemente, nessas pesquisas, identificamos também alguns dos fundamentos teóricos e metodológicos que norteiam os estudos e pesquisas nesta área. $\mathrm{Na}$ 
continuidade das pesquisas, em uma segunda fase, investigamos as genealogias dos grupos de pesquisa e seus pesquisadores, e também a respeito dos modos como são relacionados diretamente com os estudos de seus orientandos identificados com cada grupo ao qual esteve vinculado em processos de formação pós-graduada.

Os resultados dessa primeira pesquisa apontaram um crescimento das abordagens de temas sobre vida e obra de matemáticos e professores de Matemática, história das instituições, história das disciplinas escolares, dentre outras atividades sociais e culturais. Dessa tentativa de aproximação se constituem as bases das interlocuções, nas quais a diversidade de fontes na pesquisa historiográfica com origem nas teorias advindas da História, Antropologia e Sociologia estabelecem relações e implicações para uma compreensão possível acerca de uma História da Educação Matemática e das práticas socioculturais matemáticas no contexto da sociedade e da cultura (Mendes, 2012).

Com base nas informações obtidas na primeira pesquisa e analisadas posteriormente, consideramos necessário avançar nas investigações, na intenção de identificar e caracterizar uma rede de conexões de pesquisas relativamente à História da Matemática e da Educação Matemática nas décadas de 1990 a 2010 no Brasil e que se ampliaram na década de 2011 a 2018. Nesse sentido, identificamos a necessidade de redimensionar a pesquisa em direção às relações dos estudos sobre genealogia para compreender a constituição do campo de pesquisa sobre História da Educação Matemática, com vistas à possibilidade de transpor conceitos e princípios, de modo a desenhar uma cartografia pormenorizada da pesquisa em História da Educação Matemática no Brasil, com foco centralizado nos grupos de pesquisa envolvidos e suas produções, ramificações e reformulações de princípios e métodos, bem como o conhecimento produzido.

Neste artigo, apresentamos resultados e interpretações da segunda pesquisa, que concerne aos estudos sobre as genealogias dos grupos de estudo e pesquisas sobre História da Educação Matemática do Brasil, construída por educadores matemáticos em prol da organização e implementação da formação de pesquisadores nesse campo de conhecimento por meio de uma prática realizada coletivamente, além de analisar esse processo genealógico de disseminação de ideias, conceitos, princípios, fundamentos e métodos de pesquisa e de ensino.

Para tecer nossas descrições e reflexões sobre o objeto abordado neste artigo, tomamos como base epistemológica fundamentos teóricos e metodológicos concernentes à genealogia e 
à epistemologia de Ludwik Fleck (1896-1961), no tocante aos conceitos de estilo e coletivo de pensamento e gestaltsehen (ver formativo), para adentrar no contexto de constituição e institucionalização dos grupos de pesquisa. Do que tratam esses conceitos fleckianos e quais os fundamentos sobre genealogia? De que maneira poderão ser conectados para contribuir com a interpretação e caracterização do processo de formação na pesquisa em História da Educação Matemática, suas produções, ramificações e reformulações de princípios, métodos e conhecimento produzido? Para avançar no alcance das respostas às questões lançadas, apresentaremos inicialmente nossas considerações acerca de Ludwik Fleck e sua epistemologia, os conceitos advindos das teorias genealógicas adotadas na pesquisa e as conexões entre essas epistemes para explicitar a dinâmica inter e intracoletiva que envolve os grupos de pesquisa em História da Educação Matemática.

\section{Da epistemologia fleckiana e seus conceitos estruturais}

Conforme já mencionamos anteriormente, descreveremos primeiramente, de modo sucinto, o perfil e a epistemologia de Ludwik Fleck. Trata-se de um estudioso que desenvolveu, entre as décadas de 1920 a 1930, uma forma de abordar o problema do conhecimento por meio de uma epistemologia comparativa. Fleck foi um médico polonês que tinha como premissa básica que o conhecimento é fruto de processos históricos efetuados por coletivos em interação sociocultural. Assim, seu pensamento propõe categorias epistemológicas mediante as quais é possível analisar a gênese e a difusão de conhecimentos e práticas produzidos por esses coletivos, originando estilos de pensamento representativo de cada grupo em interação.

Sua epistemologia centra-se em três conceitos estruturais principais: estilo e coletivo de pensamento e gestaltsehen (ver formativo ou percepção da forma vinculada ao estilo de pensamento). Secundariamente, emergem outros conceitos, não menos importantes, como as relações inter e intracoletivas, os círculos esotéricos e exotéricos, dentre outros aspectos de extensão conceitual na teoria, que serão agenciados por nós a cada momento em que seu uso se fizer necessário nas explicações sobre o objeto investigado.

Em suas discussões sobre história, ciência e linguagem, Carlos Maia (2015), fundamentado nas teorias de Fleck, esclarece que o conceito de gestaltsehen trata do modo como percebemos o design do mundo e de que maneira se constitui cada ser histórico de forma individual e coletiva, pois é com base nessas maneiras de se colocar no mundo e olhar as coisas 
desse mundo que caracterizamos nosso ver, que atribuímos significações herdadas de gerações anteriores e que se tornarão heranças posteriores para legalizar o devir ativo-passivo ou passadofuturo.

Portanto, o Gestaltsehen nos possibilita assumir um papel ativo ou passivo em cada momento histórico de nossos encontros socioculturais por meio de uma espécie de ciclo de agenciamentos que movimentam o mundo histórico e alimentam todo e qualquer desenvolvimento, seja dos fatos, seja do saber, seja dos indivíduos, seja da própria história (Maia, 2015).

É, então, neste movimento de percepção da realidade que agimos no mundo de acordo com sua historicidade. Conforme Fleck (2010), essa maneira de ser e estar no mundo está conjugada à nossa habilidade de interação simbólica por meio do Gestaltsehen, que conjuga estratégias conceituais materializadas na teoria do ativo-passivo, no estilo e no coletivo de pensamento e na percepção das formas pelas quais esse autor desenvolve seu modelo explicativo para analisar a ciência como um diálogo entre saber e prática, originadas do coletivo em uma dinâmica de pensar coletivo que engendra o estilo de ser e estar nesse coletivo. Assim se configuram os grupos de pesquisa para constituirem-se em um coletivo de saber e de práticas investigativas.

Ainda a esse respeito, Jerzy Giedymin (1986) discorre sobre a teoria de Ludwik Fleck acerca dos estilos e coletivos de pensamento e enfatiza que os recursos e reivindicações que parecem formar o núcleo de seu programa epistemológico sugerem a rejeição da visão empirista e positivista tradicional dos fatos científicos, dada em contradição à teoria, assim como de qualquer teoria a priori ou especulativa do conhecimento, inclusive de modelos abstratos da ciência, ou seja, na forma de reconstrução lógica, como epistemologia imaginabilis (epistemologia imaginável).

Giedymin (1986) reitera que, para Fleck, há uma exigência de que a epistemologia seja empírica, com base na psicologia, história e sociologia da ciência, bem como na suposição de que todo conhecimento é socialmente determinado, uma vez que

[...] a alegação de que o conhecimento humano é desenvolvido por grupos de indivíduos em interação - pensamentos-coletivos (alguns momentâneos, outros mais estáveis) - que produzem a partir de estoques anteriores de ideias (proto-ideias) amadurecem, fecham, pelo menos em parte "incongruentes" com os sistemas anteriores e permeando - como estilos de pensamento - o pensamento dos membros individuais dos 
coletivos. Tais sistemas de crença fechados são caracterizados por forte tenacidade, apoiada sempre que necessário pela harmonia das ilusões; um indivíduo pode pertencer a mais de um coletivo de pensamento, mas é o último que é o originador e portador do conhecimento, uma vez que o conhecimento é sempre social em sua origem e caráter. Não há critérios absolutos de verdade (as verdades são as únicas soluções de problemas compatíveis com o estilo) e validade; a epistemologia deve conduzir um estudo comparativo dos estilos de pensamento (Giedymin, 1986, p. 179-180).

A experiência é, portanto, admitida como um processo complexo no qual deve ocorrer total interação entre o conhecedor, o que ele já conhece e o que está prestes a aprender, uma vez que, dos três fatores de cognição - o indivíduo, a realidade coletiva e objetiva -, um pode eliminar, enfim, um ou até dois. O coletivo, nesse processo, é composto de indivíduos. A realidade objetiva pode ser resolvida em sequências históricas de ideias pertencentes ao coletivo. No entanto, para Jerzy Giedymin (1986), o pensamento do indivíduo não pode estar em desacordo com o estilo de pensamento; portanto, só se pode prescindir do conceito de coletivo de pensamento na epistemologia introduzindo julgamentos de valor ou fé dogmática, o que não seria desejável.

Nessa dinâmica epistemológica, Fleck (1986) atribui significado ao ato de conhecer admitindo que se trata de uma atividade humana que resulta de uma construção do indivíduo em interação sociocultural, ou seja, o conhecimento é produzido em uma interação entre o sujeito e o objeto, mediada por uma dimensão que é social e culturalmente determinada. Desse modo, as relações históricas existentes em um determinado estilo de pensamento indicam que existe uma inter-relação entre o conhecido e o que se quer conhecer. Assim, Fleck (1986) considera que o já conhecido é fator condicionante na forma e na maneira de gerar um novo conhecimento, e este conhecer se expande, renova-se e dá sentido ao novo ato de conhecer.

Nessa senda, o processo de produção de conhecimento deve levar em consideração o sujeito, o objeto e o estilo de pensamento compartilhado pelo coletivo de pensamento. O estilo de pensamento é o direcionador do modo de pensar e de agir de um grupo de pesquisadores (educadores) de uma determinada área do conhecimento.

Em seus escritos, Fleck $(1986,2010)$ mostra que todo pensamento e descoberta científicos estão enraizados no estilo de pensamento dominante em uma época. São importantes descobertas produzidas pelo coletivo de pensamento e originadas da análise coletiva. O significado do indivíduo não é subestimado, mas, do ponto de vista histórico, o acúmulo de fatos 
e a formação de teorias científicas são provocados pelo trabalho em equipe e pelas qualidades da equipe, e não pelos indivíduos que a compõem.

O coletivo de pensamento compreende uma comunidade de indivíduos que compartilham práticas, concepções, tradições e normas, no qual a gestaltsehen, ou seja, a maneira própria de ver o objeto do conhecimento (o ver formativo) e de interagir com ele determina o estilo de pensamento. Na estrutura geral do coletivo de pensamento, Fleck (1986, 2010) distingue os círculos esotérico e exotérico: o primeiro é formado pelos especialistas, enquanto o segundo representa os leigos e leigos formados. As pessoas poderiam pertencer a vários coletivos simultaneamente, atuando como veículos na transmissão de ideias entre os coletivos. Entre os círculos esotérico e exotérico, estabelecem-se relações dinâmicas denominadas de circulação intracoletiva e circulação intercoletiva, que contribuem para a ampliação do campo de conhecimento.

Por meio da circulação intracoletiva de ideias, que ocorre no interior do coletivo de pensamento, o sujeito individual se insere no coletivo de pensamento e aprende a compartilhar os conhecimentos e práticas do estilo de pensamento vigente. A circulação intracoletiva de ideias é a responsável pela coerção de pensamento que forma um membro novato de determinado coletivo de pensamento. Esse tipo de circulação favorece o processo de extensão do estilo de pensamento. Já a circulação intercoletiva de ideias ocorre entre dois ou mais distintos coletivos de pensamento e tem papel fundamental na extensão do estilo de pensamento, uma vez que toda circulação intercoletiva de ideias implica um deslocamento ou transformação dos valores dos pensamentos. A comunicação não ocorre sem transformação e sem que se produza uma remodelação de acordo com o estilo, que, em termos intercoletivos, traduz-se em um reforço, e, numa ótica intercoletiva, em uma mudança fundamental do pensamento comunicado.

\section{Formativo na pesquisa em História da Educação Matemática}

A partir do que foi mencionado na seção anterior, podemos destacar que a epistemologia fleckiana possibilita compreender os modos de praticar o processo coletivo da produção do conhecimento nos grupos e entre grupos de pesquisa em História da Educação Matemática. Ao mesmo tempo, possibilita compreender que a maneira de um pesquisador realizar a sua prática investigativa está relacionada ao seu processo de formação como pesquisador. Igualmente, permite identificar condições para a instauração de um estilo de pensamento ligado à pesquisa 
em História da Educação Matemática relativamente a cada grupo examinado. Nesse sentido, propicia a compreensão da importância da comunicação intra e intercoletiva no estabelecimento e transformação de um estilo de pensamento e o impacto da formação docente para o ingresso em um estilo de pensamento e na constituição do campo de pesquisa em Educação Matemática.

Assim sendo, nesta seção, consideramos relevante destacar aspectos acerca da História da Educação Matemática brasileira que se caracterizam pela apresentação dos itinerários da constituição das comunidades de educadores matemáticos em prol da organização e implementação de um modelo próprio de formação de pesquisadores nesse campo de conhecimento por meio de uma prática pensada e realizada coletivamente. Esse exercício nos levou a interpretar a organização dos grupos de pesquisa como comunidades investigativas a partir do conceito de coletivo de pensamento de Fleck, conforme discutido na seção anterior. Todavia, é necessário explicitar em quais sentidos as práticas de pesquisa desenvolvidas nesses grupos se caracterizam como uma produção coletiva que reflete os princípios teóricos que sustentam as investigações dos grupos.

Para falar das características e potencialidades das ações dos grupos de pesquisa em História da Educação Matemática, buscamos apoio na epistemologia de Ludwik Fleck, tomando-a referência para enfocar aspectos teórico-metodológicos concernentes à formação de pesquisadores. Do que se trata, afinal?

No entender de Fleck, os conceitos com os quais o cientista trabalha dependem de "proto-ideias" ou "pré-ideias", muitas vezes précientíficas e obscuras, retiradas de outras ideias, da religião, da arte, etc. Neste sentido, os conceitos nunca podem ser produzidos espontaneamente, mas constituem-se como resultado de um desenvolvimento histórico. Por isso Fleck afirma que naõ é possível, de nenhum modo, cortar os laços com a história" (Bombassaro, 1992, p. 96).

Conforme já foi mencionado na seção anterior, para Fleck (1986), o conhecimento resulta de uma construção do indivíduo em interação sociocultural. Dito de outro modo, o conhecimento se dá em uma interação entre o sujeito e o objeto mediada por uma dimensão socioculturalmente determinada. As relações históricas existentes em um determinado estilo de pensamento indicam que existe uma inter-relação entre o conhecido e o que se quer conhecer, pois, para o referido autor, o já conhecido condiciona a forma e a maneira do novo conhecimento, como também a forma como esse conhecer expande, renova e dá sentido ao novo 
conhecer. Assim, o processo de produção de conhecimento deve levar em consideração o sujeito, o objeto e o estilo de pensamento compartilhado pelo coletivo que comunga do estilo, porquanto este é o direcionador do modo de pensar e de agir de um grupo de pesquisadores de uma dada área do conhecimento; em nosso estudo, o campo de pesquisa em História da Educação Matemática (Mendes; Farias, 2015).

O coletivo de pensamento compreende uma comunidade de indivíduos que compartilham práticas, concepções, tradições e normas, na qual a maneira própria de ver o objeto do conhecimento (o ver formativo) e de interagir com ele determina o estilo de pensamento, que passa do círculo esotérico ao exotérico, de modo a possibilitar, então, as interações entre esses coletivos simultaneamente, além da transmissão de ideias entre coletivos por meio de circulação intra e intercoletiva.

Através da circulação intracoletiva de ideias, que ocorre no interior do coletivo de pensamento, o sujeito individual se insere no coletivo. Ele precisa aprender e compartilhar os conhecimentos e práticas do estilo de pensamento vigente. A circulação intracoletiva de ideias é responsável pela coerção de pensamento que forma um membro novato de determinado coletivo de pensamento. Este tipo de circulação contribui para o processo de extensão do estilo de pensamento.

A circulação intercoletiva de ideias ocorre entre dois ou mais distintos coletivos de pensamento e tem papel fundamental na extensão do estilo de pensamento, uma vez que toda circulação intercoletiva de ideias implica um deslocamento ou transformação dos valores dos pensamentos. A comunicação não ocorre sem transformação e sem que se produza uma remodelação de acordo com o estilo, que, na ótica intercoletiva, traduz-se em um reforço, e, em termos intercoletivos, em uma mudança fundamental do pensamento comunicado.

A solução fleckiana reúne os dois lados em disputa (Sociedade ou Natureza?) em uma alternativa mais fiel à história: os indivíduos sociais possuem um papel ativo (como quer o relativismo sociológico), mas também sofrem o agenciamento dos objetos naturais (como quer o realismo cientificista). Este é o agenciamento recíproco (Condé, 2012, p. 73).

De modo interpretativo, podemos considerar que a epistemologia de Fleck (1986, 2010) possibilita compreender a importância da comunicação intra e intercoletiva no estabelecimento e transformação histórica de um estilo de pensamento. No caso da pesquisa em 
história da Educação Matemática, poderá estimular a inserção dessas práticas nos currículos da graduação visando a formar professores que, por meio da pesquisa, exercitem uma reflexão sobre a história das práticas pedagógicas dos professores de Matemática em diferentes épocas e locais, com vistas a adquirir habilidades de análise do impacto de uma formação dada ao professor para que ele incorpore um estilo de pensamento característico de um coletivo que represente as ações institucionalizadas pelo campo da Educação Matemática. Nessa perspectiva, abordaremos aspectos relativamente aos grupos de pesquisa em História da Educação Matemática na interface característica de um coletivo de pensamento.

\section{Os grupos de pesquisa em História da Educação Matemática como coletivo de pensamento}

O desenvolvimento dos nossos estudos atuais leva em consideração ser extremamente relevante explorar e destacar aspectos da História da Educação Matemática brasileira, que se caracterizam pela apresentação dos itinerários da constituição das comunidades de educadores matemáticos, desafiadores e empreendedores em prol da organização e implementação de um modelo próprio de concretização da formação de pesquisadores em Educação Matemática por meio de uma prática pensada e realizada coletivamente, que nos levou a interpretar a organização dos grupos de pesquisa a partir de um coletivo de pensamento, como sugere Fleck (1986, 2010). A partir de quais aspectos podemos nos questionar sobre os sentidos da produção coletiva que refletem princípios teóricos sustentadores desses grupos?

Para falar das características e potencialidades das ações dos grupos de pesquisa em História da Educação Matemática, buscamos apoio nas contribuições presentes na epistemologia de Fleck (1986, 2010), tomando-as referência para enfocar aspectos teóricos e metodológicos concernentes à formação de pesquisadores em Educação Matemática, especificamente sobre História da Educação Matemática.

Na epistemologia fleckiana, o conhecimento é resultado de um processo de construção do indivíduo em interação sociocultural, ou seja, o conhecimento se desenvolve por meio de uma interação entre o sujeito e o objeto mediada por uma dimensão, que é social e culturalmente determinada. As relações históricas existentes em um determinado estilo de pensamento indicam que existe uma inter-relação entre o conhecido e o que se quer conhecer. Logo, o que já é conhecido pode condicionar a maneira de produzir o novo conhecimento e o modo de configurar tal conhecimento (estilo de pensamento), e esse conhecer se expande, renova-se e dá sentido ao novo conhecer. 
Assim, o processo de produção de conhecimento deve levar em consideração o sujeito, o objeto e o estilo de pensamento compartilhado pelo coletivo de pensamento. Esse estilo de pensamento, portanto, é a base do princípio direcionador do modo de pensar e de agir de um grupo de pesquisadores (educadores) de uma determinada área do conhecimento. Para Fleck (1986, 2010), o coletivo de pensamento compreende uma comunidade de indivíduos que compartilham práticas, concepções, tradições e normas, cuja maneira própria de ver o objeto do conhecimento (o ver formativo) e de interagir com ele determina o estilo de pensamento. Na estrutura geral do coletivo de pensamento, Fleck $(1986,2010)$ distingue dois círculos de interação: o esotérico e o exotérico. O primeiro é composto pelos especialistas, enquanto o segundo incorpora os não especialistas, ou seja, os leigos e os leigos formados. Todavia, as pessoas podem pertencer a vários coletivos de pensamento simultaneamente, de modo a acarretar uma atuação determinante no processo de transmissão de ideias entre os coletivos.

Nesse sentido, Fleck (1986, 2010) esclarece ser entre os círculos exotérico e esotérico que são estabelecidas algumas relações dinâmicas que podem contribuir para a ampliação da área de conhecimento. Fleck $(1986,2010)$ denomina esse movimento de circulação intracoletiva e circulação intercoletiva. É por meio da circulação intracoletiva de ideias, ocorrida no interior do coletivo de pensamento, que o sujeito individual se insere no coletivo de pensamento e, a partir daí, precisa aprender e compartilhar conhecimentos e práticas do estilo de pensamento vigente.

Essa circulação intracoletiva de ideias é responsável pela coerção de pensamento que formam um membro novato de determinado coletivo de pensamento, contribuindo, então, para o processo de extensão do estilo de pensamento. Já a circulação intercoletiva de ideias ocorre entre dois ou mais distintos coletivos de pensamento e desempenha um papel fundamental na extensão do estilo de pensamento, haja vista que toda circulação intercoletiva de ideias implica um deslocamento ou transformação dos valores dos pensamentos.

Podemos considerar, então, que a epistemologia de Fleck (1986, 2020) nos possibilita identificar o caráter sócio-histórico-cultural da produção do conhecimento e assim compreender a interação dos coletivos dos pesquisadores e de professores entre si e com outros grupos sociais, explicitando o caráter sociológico da produção e disseminação do conhecimento científico. As categorias circulação intra e intercoletiva de ideias possibilitam caracterizar os processos de constituição, disseminação e modificação do conhecimento. Desse modo, permitem identificar 
as condições para a instauração de um estilo de pensamento ligado à Educação Matemática e propiciam compreender a importância da comunicação intra e intercoletiva no estabelecimento e transformação de um estilo de pensamento. Além disso, estimulam a inserção da História da Ciência (da Matemática e da Educação Matemática) nos currículos do curso de Licenciatura em Matemática, visando à formação de professores, tal como ocorre em alguns cursos de licenciatura em Matemática do Brasil a partir da década de 1990. A inserção dessas histórias (da Matemática e da Educação Matemática), consequentemente, estimulou os pesquisadores a uma reflexão sobre a prática pedagógica dos professores, de modo a analisar o impacto da formação do professor para o ingresso em um estilo de pensamento e na constituição da área de Educação Matemática na ação docente.

De acordo com a epistemologia de Fleck (1986, 2010), podemos considerar que a condução acadêmica adotada pelos membros de um coletivo de pensamento a partir do ingresso no grupo está diretamente imbricada no percurso profissional delineado em suas carreiras. Isto porque o coletivo oportuniza a aprendizagem do diálogo, a mudança e o desenvolvimento profissional, por meio de uma dinâmica de formação, um movimento autônomo e crítico, admitido como uma necessidade de ampliação dos saberes profissionais.

A epistemologia de Fleck $(1986,2010)$ possibilita identificar o caráter sócio-históricocultural da produção do conhecimento e compreender a interação dos coletivos de cientistas e de professores entre si e com outros grupos sociais, explicitando o caráter sociológico da produção e disseminação do conhecimento científico. Além disso, propõe que as categorias de circulação intra e intercoletiva de ideias possibilitam caracterizar os processos de constituição, disseminação e modificação do conhecimento, pois assim se torna possível conhecer o pensamento e as práticas pedagógicas dos professores, uma vez que a produção do conhecimento se caracteriza como um processo que envolve instauração, extensão e transformação de estilos de pensamento. Tal processo de instauração de um estilo de pensamento decorre do enfrentamento de um problema por mais de um pesquisador, ou seja, por um coletivo.

Igualmente, tomamos a epistemologia de Fleck (1986, 2010) para caracterizar os grupos de pesquisa a considerar que a condução acadêmica é adotada pelos membros de cada grupo a partir do ingresso nesse coletivo e está diretamente imbricada no percurso profissional delineado em suas carreiras. No processo de historicidade da formação dos membros desse 
coletivo, são-lhes oportunizadas a aprendizagem do diálogo, a mudança e o desenvolvimento profissional. Assim, a dinâmica de formação se mostra como um movimento autônomo e crítico que denota a necessidade de ampliação dos saberes profissionais para a pesquisa e que são constituídos no coletivo e expressados por meio de um estilo de pensamento que também representa o coletivo, normalmente materializado nos conceitos, fundamentos e métodos adotados para tratar dos objetos de estudo, bem como nos modos de ser e agir no grupo.

A partir daí, a atividade prática em pesquisa deve ser tomada como norteadora para a constituição de um estilo de pensamento no exercício formativo da pesquisa em História da Educação Matemática. Portanto, a partir dessas reflexões, podemos admitir que o pensamento de Fleck pode ser tomado como referencial para a pesquisa praticada pelos grupos, como também e para tentar compreender e explicar o processo de criação desses grupos em suas práticas e exercícios do coletivo de pensamento em História da Educação Matemática, com vistas às suas implicações na organização de palestras, oficinas, cursos e seminários que estabeleçam um estilo de pensamento nas comunidades educativas do país. Foi com base nesses aspectos que procuramos investigar e caracterizar as dinâmicas de três grupos considerados basilares na formação de pesquisadores no campo da História da Educação Matemática.

\section{Do conceito de genealogia dos grupos de pesquisa}

Para avançar em nossas discussões e reflexões, é necessário tratar do conceito de genealogia, tendo em vista compreender sobre o surgimento e a organização dos grupos de pesquisa, a ação dos pesquisadores envolvidos e suas produções, desde a década de 1990. Neste caso, a genealogia é tomada como uma ciência auxiliar da História que aponta a origem, evolução e disseminação dos grupos como organizações sociais e institucionais em várias gerações. Desenvolve-se no âmbito da história e memória desses grupos, fundamentando-se na Sociologia, na Antropologia, na Economia e na História da Arte (Archassal, 2000). Para alguns teóricos, a genealogia tem como objetivo desvendar as origens das pessoas e famílias por intermédio do levantamento sistemático de seus antepassados ou descendentes, local onde nasceram e viveram e seus relacionamentos interfamiliares.

Como sabemos, muitos nomes de família dependeram da competência e discrição de quem os fez no ato do registro da história dos ancestrais, sob a forma de texto ou árvore genealógica, com nomes, datas e lugares por onde eles passaram para conhecimento de seus 
descendentes. A base desse tipo de pesquisa é encontrar no passado ligações entre pessoas de diversas etnias, credos e classes sociais, a partir de informações levantadas em diversos documentos para que se torne possível construir a árvore genealógica de cada pessoa ou grupo social, de forma que sejam mantidos vivos na memória de seus descendentes e possam explicar o processo de constituição de um modelo sociocultural, político e filosófico.

Para organizar informações sobre a genealogia dos grupos, tomamos a ideia de GrupoPai, que, em nosso estudo, é representado pelo grupo ao qual o pesquisador foi vinculado durante sua formação pós-graduada, principalmente o doutorado. Nessa representação, entendemos que a herança adquirida no decurso da formação doutoral possibilita ao membro de cada grupo associar a essa formação as referências teóricas do Grupo-Pai, seus princípios, fundamentos e métodos, bem como os modos de instituicionalização e constituição do estilo de pensamento incorporado a partir desse grupo.

O estudo genealógico possibilita compreender a organização e hierarquização dos processos hereditários no grupo, uma vez que é por meio das interações socioculturais vivenciadas no Grupo-Pai que ocorrem circulações intra e intercoletivas de ideias entre os membros de cada Grupo-Pai e os seus descendentes, bem como entre dois ou mais distintos grupos-pais (coletivos de pensamento), para fortalecer o exercício fundamental na extensão do estilo de pensamento, pois tais circulações implicam deslocamentos ou transformações de conceitos estabelecidos intra e intercoletivos, os quais formarão o gestaltsehen do pesquisador em formação (seu ver formativo). Isto porque, segundo Fleck (2010), a comunicação não ocorre sem transformação e sem que se produza uma remodelação de acordo com o estilo, que intracoletivamente se traduz em um reforço e, intercoletivamente, em uma mudança fundamental do pensamento comunicado entre grupos.

Há, portanto, necessidade de se compreender como surgem os ramos, ou seja, os descendentes das epistemologias dos Grupos-Pai, vale dizer, as possíveis bifurcações dos formatos herdados, fazendo surgir o formato filho, que, embora não se desligue do tronco representado pelo formato-pai, faz surgir a ciência filha, isto é, uma ciência com as características do tronco, mas com novos direcionamentos intencionalizados pelo que se quer alcançar. Trata-se de adotar o formato pai ou o formato ciência filha, conforme argumenta Michel Serres (2008), com implicações no estilo de pensamento estabelecido em um coletivo, 
conforme conexões epistemológicas implícitas nas argumentações de Ludwick Fleck (2010) ao tratar da gênese e desenvolvimento de um fato científico.

Particularmente, as análises realizadas a respeito dessas pesquisas demonstraram que, nos estudos concretizados para dissertações e teses, há uma ampla abrangência epistemológica, sociológica e pedagógica, permeada por diferentes linhas de abordagem intimamente ligadas e que caracterizam os fundamentos e métodos de investigação utilizados nos grupos de pesquisa, de modo a caracterizar estilos e coletivos de pensamento (Fleck, 2010) que são disseminados após as conclusões dos estudos pós-graduados, apontando a constituição genealógica adquirida nessa formação, o que possibilita ao descendente operar ramificações e bifurcações dos formatos pai para a criação de uma ciência filha, conforme assevera Serres (2008).

Um exemplo desse movimento sociocognitivo relativamente ao pensamento, reflexão e ação na pesquisa e na formação do pesquisador em grupos representantes desses coletivos de pensamento são expressos nas reuniões de estudos desses grupos, em eventos de divulgação e disseminação de resultados de pesquisas, como congressos, seminários, palestras, oficinas, cursos ou similares, cujas atividades são socialmente planejadas para que sejam estabelecidas disseminações de estilos de pensamento nas comunidades educativas do país.

Mediante tal perspectiva, fizemos um levantamento inicial sobre os grupos de pesquisa do Brasil voltados à História da Educação Matemática, a fim de selecionar, organizar, analisar e catalogar cada um, com o fito de compor um banco de informações que possam caracterizar a área em estudo, suas dimensões, desmembramentos e ramificações. A partir desse levantamento, poderemos vislumbrar a construção das redes de conexão de pesquisadores em História da Educação Matemática e das conexões entre pesquisadores, estudantes de mestrado e doutorado, suas respectivas linhas de pesquisa e produções geradas durante a pós-graduação e após a sua inclusão no sistema de pesquisa em História da Educação Matemática no Brasil (Mendes; Farias, 2015).

Assim, os grupos de pesquisa em História da Educação Matemática precisam ter claramente definidas as suas afiliações filosóficas e intenções epistêmicas, para que seus grupos descendentes possam, posteriormente, configurar os seus como um ramo novo, no mesmo caule ou a partir de uma enchertia agregada ao caule ou ao tronco do formato-pai (Serres, 2008). Estas foram algumas das preocupações que nos fizeram percorrer um caminho investigativo acerca do desenvolvimento das pesquisas materializadas nas escritas de dissertações, teses, artigos e 
outras produções científicas geradas em grupos de pesquisa em História da Educação Matemática do Brasil.

\section{Sobre os grupos de pesquisa em história da Educação Matemática}

De acordo com um projeto desenvolvido no CNPq desde 1992, o Diretório dos Grupos de Pesquisa no Brasil constitui-se em bases de dados que contêm informações sobre os grupos de pesquisa em atividade no país. Nesse diretório, as informações são atualizadas continuamente pelos líderes de grupos, pesquisadores, estudantes e dirigentes de pesquisa das instituições participantes, e o CNPq realiza censos bienais, que são uma espécie de imagem da base corrente do diretório, que se refere à constituição dos grupos (pesquisadores, estudantes e técnicos), às linhas de pesquisa em andamento, às especialidades do conhecimento, aos setores de aplicação envolvidos, à produção científica e tecnológica e aos padrões de interação com o setor produtivo. Além disso, cada grupo é situado no espaço (região, UF e instituição) e no tempo (CNPq, 2018).

O Diretório dos Grupos de Pesquisa é um eficiente instrumento para o intercâmbio e a troca de informações. Com precisão e rapidez, é capaz de responder quem é quem, onde se encontra, o que está fazendo e o que produziu recentemente, seja no nível das instituições, seja no das sociedades científicas ou ainda no das várias instâncias de organização políticoadministrativa do país. A base de dados do Diretório é uma fonte inesgotável de informação (CNPq, 2018).

A definição metodológica mais importante na constituição da base de informações é a de sua unidade de análise. Teoricamente, um grupo de pesquisa é considerado como um conjunto de indivíduos organizados hierarquicamente, cuja base de organização se centra na experiência, no destaque e na liderança no campo científico ou tecnológico em que os membros estão envolvidos profissionalmente e com atividades permanentes de pesquisa, com trabalho organizado em torno de linhas comuns de pesquisa e que, em algum grau, compartilham instalações e equipamentos. Cada grupo de pesquisa está organizado em torno de uma liderança (eventualmente duas), que é a fonte das informações constantes na base de dados.

Na quase totalidade dos casos, esses grupos são compostos pelo pesquisador líder (quase sempre o orientador) e de seus estudantes (mestrandos e, principalmente, os doutorandos). No processo interativo entre os elementos do grupo, Fleck (2010, p. 131) assevera que, "quanto mais se entra numa área científica, tanto maior se torna o vínculo com o coletivo de pensamento e tanto maior a ligação imediata com o pesquisador" (líder do grupo), aumentando, assim, os 
elementos ativos do saber instituído nesse grupo, com prováveis possibilidades de disseminação, ramificação ou reinvenção desses saberes instituídos quando os descendentes formarem suas famílias, ou seja, seus grupos-filhos ou seus novos coletivos de pensamento. É nesse fluxo que procuramos olhar o movimento desenhado no Diretório do $\mathrm{CNPq}$, tomando três grupos-base para destacar neste artigo, a considerar sua representatividade em todo o coletivo ao qual faz parte na comunidade acadêmica que pesquisa em História da Educação Matemática.

Neste artigo, portanto, apresentamos tão-somente informações sobre uma amostra de três grupos considerados Grupos-Pais (HIFEM, GHEMAT e GHOEM), que desenvolvem estudos e pesquisas voltados à área de História da Educação Matemática, pertencentes às instituições de ensino superior e a institutos de pesquisa que possuem programas de pós-graduação nas áreas de Educação, Educação Matemática ou Ensino de Ciências e Matemática. A escolha desses grupos foi definida com base nos objetivos da pesquisa, nas abordagens de pesquisa dos grupos e no tempo de formação e de suas linhas de pesquisa, porquanto esses são os grupos que expressam a formação de pesquisadores para as diversas regiões geográficas do Brasil, em suas genealogias, ramificações e difusão de conhecimentos produzidos nesse campo. Para a construção das genealogias dos grupos, e tomando as informações presentes no Diretório dos Grupos do CNPq e no Currículos Lattes dos pesquisadores investigados, foi possível identificar os doutores formados no grupo, que se reinventaram de modo a criar novos grupos para atuarem como pesquisadores autônomos, mas, muitas vezes, em conexão de cooperação.

\section{Grupo de pesquisa História, Filosofia e Educação Matemática (HIFEM $)^{1}$}

O HIFEM constituiu-se em 1996, com o objetivo fundamental de desenvolver investigações e ações acerca das inter-relações entre História, Filosofia e Educação Matemática. Até 2016, o grupo foi coordenado por Maria Ângela Miorim (UNICAMP), embora seja um grupo interinstitucional. Em mais de duas décadas de existência, o HIFEM desenvolveu projetos individuais ou coletivos nas seguintes temáticas: 1) História e Filosofia da Educação Matemática, particularmente da Educação Matemática brasileira; 2) Processos de produção, transmissão e apropriação da Matemática em diferentes épocas, práticas sociais e contextos institucionais, sobretudo o escolar; 3) História e Filosofia na Educação Matemática. O grupo

\footnotetext{
${ }^{1}$ Quase todas as informações mencionadas sobre o grupo foram extraídas do diretório do CNPq, do Currículo Lattes de seus líderes e de algumas publicações de membros do grupo.
} 
conta atualmente com a participação de seis pesquisadores e 17 estudantes, organizados em seis linhas de pesquisa: Educação Matemática e Sociedade; Estudos Histórico-Pedagógicos Temáticos em Educação Matemática; Filosofia da Educação Matemática; Filosofia na Educação Matemática; História da Educação Matemática e História na Educação Matemática.

Os dois pesquisadores pioneiros do HIFEM nas orientações de doutorado foram Maria Ângela Miorim e Antonio Miguel, considerados na genealogia como a base, a raiz do grupo, os pais formadores dos descendentes do grupo, que se inseriram no sistema de pesquisa e ensino superior no país e que foram identificados no Diretório dos Grupos de Pesquisa do CNPq como membros participantes ou egressos, os quais são os representantes do pensamento do HIFEM.

Com formação em Matemática (Bacharelado e Licenciatura), mestrado em Matemática e doutorado em Educação, a pesquisadora Maria Ângela Miorim, coordenou o HIFEM da FEUNICAMP desde a sua criação, em 1996, até 2018, em paralelo à docência no Departamento de Ensino e Práticas Culturais da Faculdade de Educação, como também nos Programas de PósGraduação em Educação e no Multiunidades em Ensino de Ciências e Matemática, com orientações de doutorado até 2018.

O pesquisador Antonio Miguel, graduado em Licenciatura em Matemática, mestrado e doutorado em Educação, desde 1982 atuou na docência do Departamento de Ensino e Práticas Culturais da Faculdade de Educação da UNICAMP, além de orientar no Programa de PósGraduação em Educação da Faculdade de Educação e junto ao Programa de Pós-Graduação Multiunidades em Ensino de Ciências e Matemática. Atualmente, encontra-se aposentado. Contudo, continua seus estudos, pesquisa e orientações na pós-graduação na UNICAMP. Destaca-se com pesquisas relacionadas às linhas de Educação em Ciências, Matemática e Tecnologias; Linguagem e Arte em Educação; e História, Filosofia e Linguagem, sendo esta última caracterizada por investigações que adentram a construção do conhecimento em Ciências da Natureza e Matemática, bem como no seu ensino.

A orientação metódica pós-estruturalista e pós-colonialista que tem adotado para lidar com problemas e questões de investigação no interior dessas linhas de pesquisa é denominada de atitude terapêutico-desconstrucionista, que não é vista nem como uma teoria nem como um método genérico com etapas previamente determinadas, mas como uma orientação metódica que assume formas idiossincráticas para cada pesquisa. 
Figura 01. Mapa de abrangência da formação de doutores e ação coletiva em pesquisa, realizada pelo HIFEM até fevereiro de 2018.

Mapa genealógico, ramificações e descendentes do HIFEM

Organizado a partir das informações obtidas na pesquisa até fevereiro de 2018.

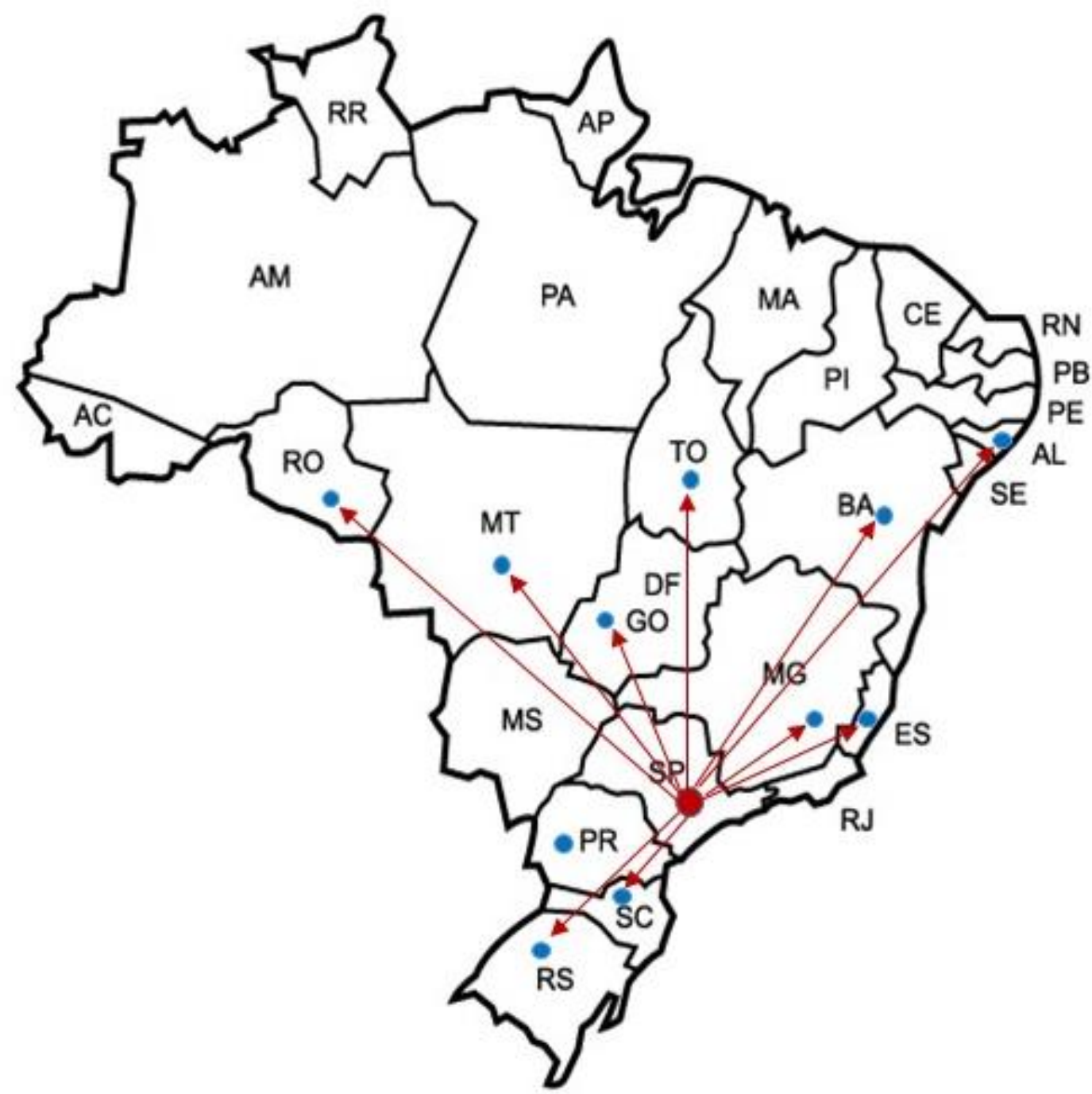

Fonte: Elaboração dos pesquisadores a partir dos documentos da plataforma Lattes e diretório dos grupos do CNPq. 
Figura 02. Fluxo genealógico da formação de doutores e atuação coletiva em pesquisa, em conexão com o HIFEM até fevereiro de 2018.

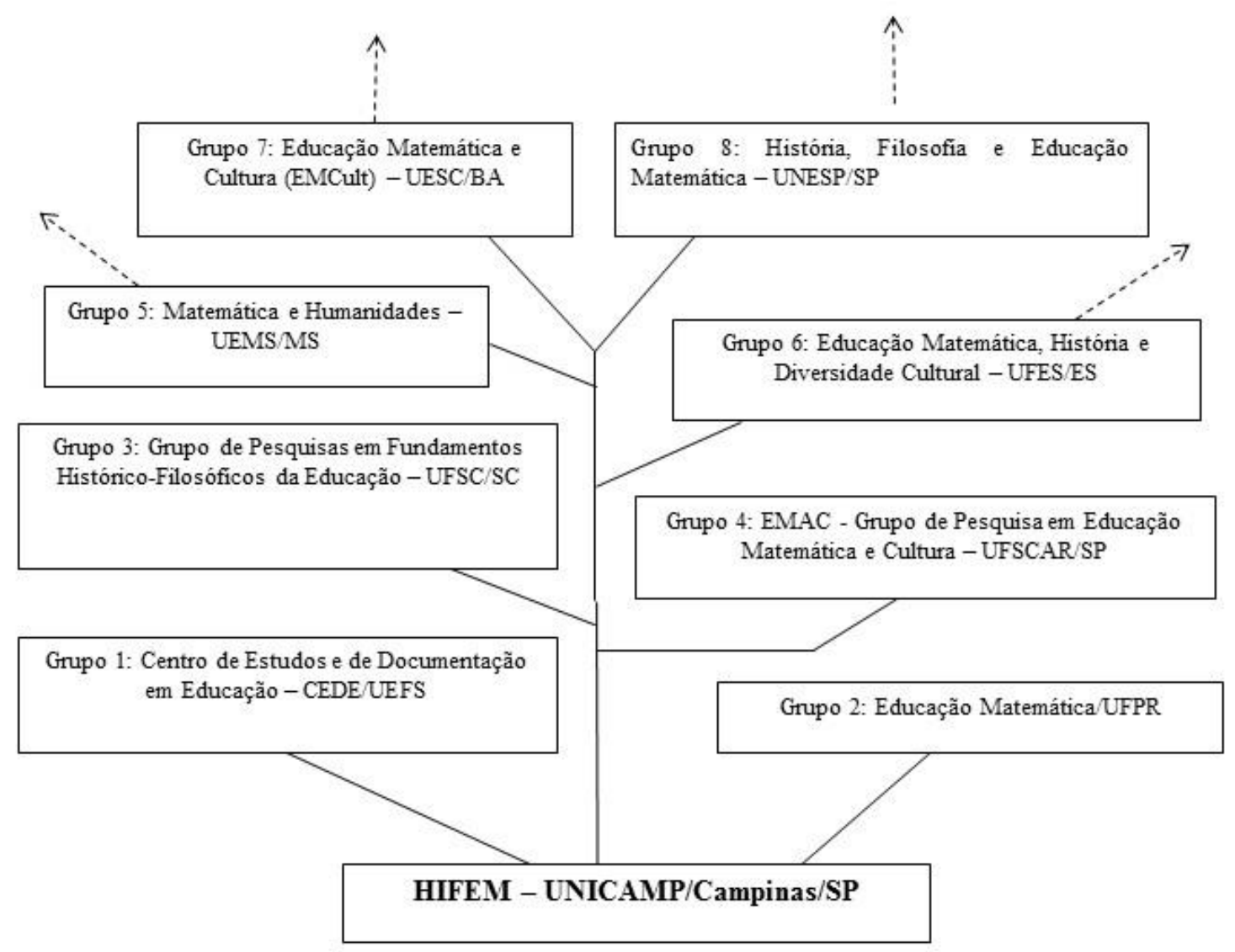

Fonte: Elaboração dos pesquisadores a partir dos documentos da Plataforma Lattes e do Diretório dos Grupos de Pesquisas do CNPq.

Atualmente o site do HIFEM para divulgação de informações relativas às pesquisas, ações e produções do grupo é o seguinte: https://www.fe.unicamp.br/hifem/.

\section{Grupo de Pesquisa de História da Educação Matemática no Brasil (GHEMAT)²}

O GHEMAT foi criado no ano 2000 pelo professor Wagner Rodrigues Valente, na área de Educação. Atualmente vinculado à Universidade Federal de São Paulo (UNIFESP), Curso de Pedagogia, campus Guarulhos. Esse grupo reúne pesquisadores de diversos estados brasileiros e universidades do país e destaca-se pelo desenvolvimento coletivo de projetos

\footnotetext{
${ }^{2}$ A quase totalidade das informações mencionadas sobre o grupo foi extraída do Diretório do CNPq, do Currículo Lates de seus líderes e de algumas publicações de membros do grupo. Anteriormente, muitas dessas informações também aparecem em um artigo de autoria de Mendes e Farias (2018), publicado na Revista Paradigma, v. 39, jun. 2018 (mencionado nas referências, ao final deste artigo), tendo sido necessário retomá-las aqui.
} 
temáticos de pesquisa sobre Educação Matemática nos diversos níveis de escolaridade: História do Ensino de Matemática, dos conteúdos, dos livros didáticos, da disciplina Matemática e da formação de professores que ensinam essa disciplina são alguns dos temas desenvolvidos nos projetos de pesquisa. Em 2008, o GHEMAT criou o seu Centro de Documentação, cujo acervo consta de arquivos pessoais de educadores matemáticos como Euclides Roxo, Osvaldo Sangiorgi, Ubiratan D’Ambrosio, Scipione Di Pierro Netto, Lucília Bechara Sanchez, Manhúcia Liberman dentre outros. Também fazem parte do acervo, documentação que registra práticas escolares do ensino de matemática de outros tempos como: cadernos de alunos, cadernos de professores, livros didáticos de matemática, exames e provas. O Centro encontra-se aberto ao público e pesquisadores em geral, a partir do agendamento de visitas pelo site <www.unifesp.br/centros/ghemat>.

O GHEMAT desenvolve atividades periódicas de pesquisa e formação continuada de professores, em especial, de matemática. As primeiras, ligam-se aos trabalhos semanais realizados no Centro de Documentação e encontros do Grupo, presenciais ou por meio dos chamados "seminários on-line". A formação continuada de professores relaciona-se aos encontros denominados Ciclo de Seminários, onde especialistas encontram estudantes de licenciatura e professores de matemática para debaterem temas da educação matemática. $\mathrm{O}$ grupo é composto atualmente por dezoito pesquisadores de diferentes instituições de ensino superior brasileiras e treze estudantes, organizados na linha de pesquisa História da Educação Matemática, cujo objetivo é desenvolver pesquisas com vistas à compreensão histórica do ensino e aprendizagem da matemática, da formação de professores de matemática e do trajeto de constituição da matemática escolar (Mendes; Farias, 2018).

Pesquisadores representantes do estilo de pensamento do grupo

O pesquisador Wagner Rodrigues Valente é líder do GHEMAT. Atua com pesquisas na área de Educação, em especial no campo História da Educação Matemática, e presentemente investiga sobre a história dos saberes elementares matemáticos da escola primária, a constituição dos experts e expertises nesse contexto de ensino desses saberes. É o principal acionador das ações investigativas do grupo na constituição de seu coletivo e estilo de pensamento, com vistas à formação de pesquisadores e sua ramificação e disseminação em diversas regiões do Brasil, com cooperação internacional em pesquisa com países como Portugal (2006-2009) e França (2014-2017), além de supervisionar pesquisas de mestrado, doutorado e pós-doutorado. 
A pesquisadora Neuza Bertoni Pinto é vice-líder do GHEMAT e atua com pesquisas na área de Educação, principalmente no campo História da Educação Matemática. Atualmente, investiga o Movimento da Matemática Moderna, a história dos saberes elementares matemáticos da escola primária e história das disciplinas escolares, saberes que apoiam seus estudos de relevância para a atual configuração do cenário brasileiro.

Os projetos desses pesquisadores preocupam-se em compreender os saberes elementares matemáticos (Aritmética, Geometria e Desenho), de modo a verificar como foram apropriados pelo ensino das escolas primárias (1903 a 1971) a partir de fontes como revistas e/ou manuais pedagógicos, livros didáticos, atas, legislação educacional, dentre outras fontes documentais que contribuem para o processo investigatório intencionado pelo grupo. Destacamos, ainda, que o foco desses estudos recai sobre a história da matemática escolar, utilizando referenciais conceituais da história cultural.

Atualmente, o site do GHEMAT para a divulgação de informações relativas às pesquisas, ações e produções do grupo é: http//:www.unifesp.br/centros/ghemat. 
Figura 03. Mapa de abrangência da formação de doutores e ação coletiva em pesquisa, realizada pelo GHEMAT até fevereiro de 2018.

Mapa genealógico, ramificações e descendentes do GHEMAT

Organizado a partir das informações obtidas na pesquisa até fevereiro de 2018.

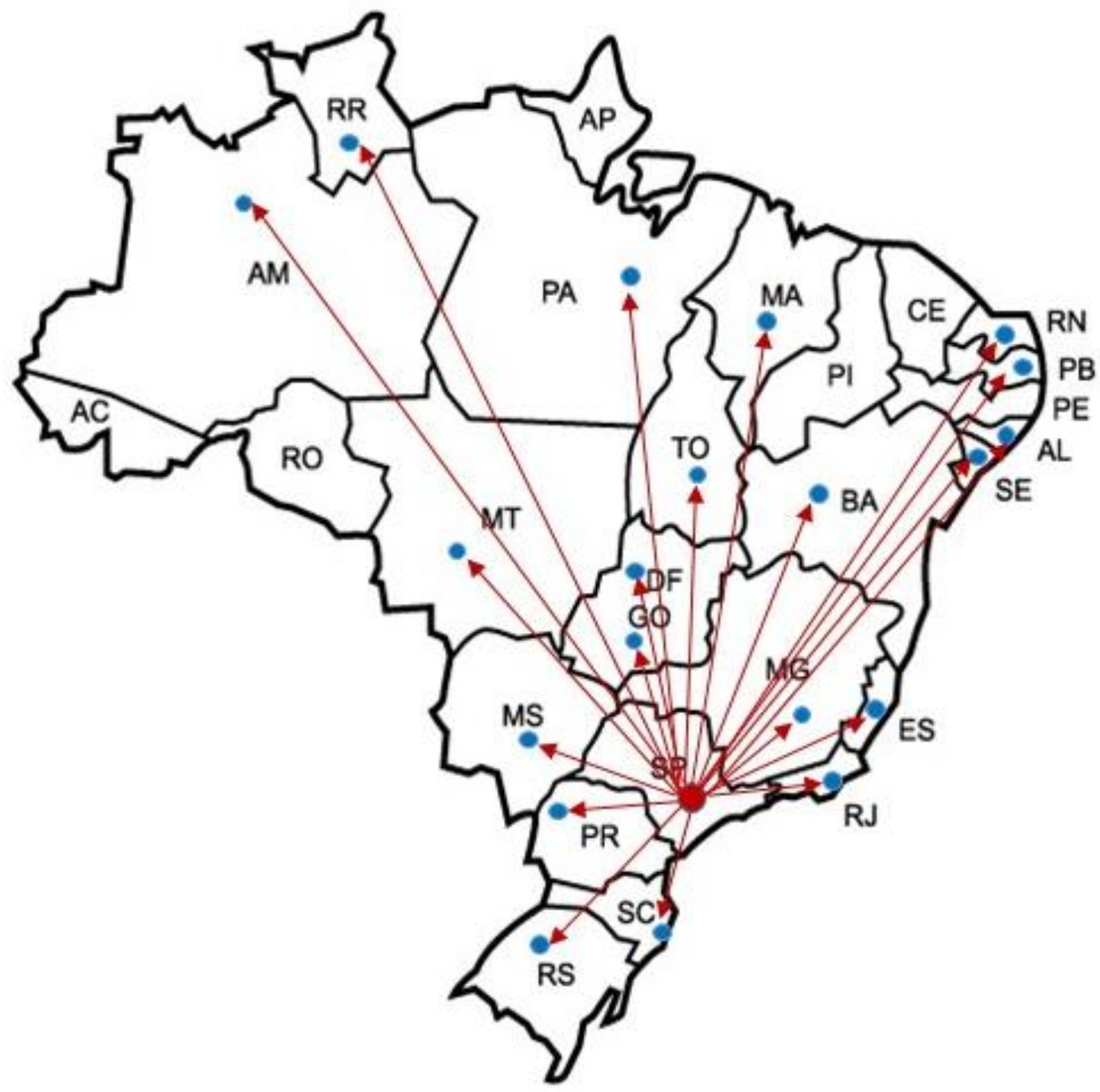

Fonte: Elaboração dos pesquisadores a partir dos documentos da plataforma Lattes e diretório dos grupos do CNPq. 
Figura 04. Fluo genealógico da formação de doutores e atuação coletiva em pesquisa, em conexão com o GHEMAT até fevereiro de 2018.

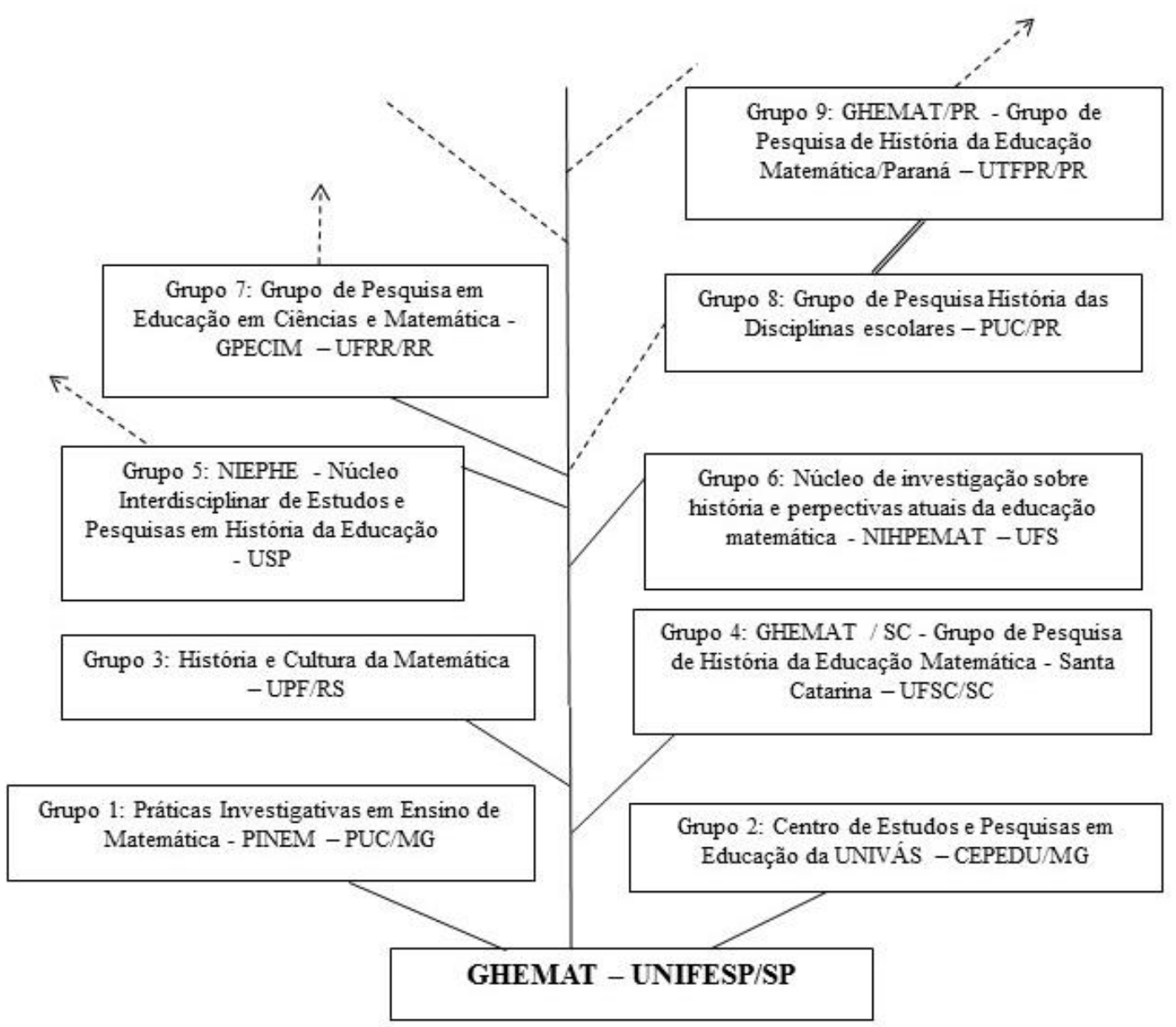

Fonte: Elaboração dos pesquisadores a partir dos documentos da plataforma Lattes e diretório dos grupos do CNPq.

\section{Grupo História Oral e Educação Matemática (GHOEM) ${ }^{3}$}

O GHOEM foi criado em 2002 e atualmente é coordenado pelos professores Antonio Vicente Marafioti Garnica e Heloisa da Silva, na área de Educação Matemática, na Universidade Estadual Paulista Júlio de Mesquita Filho (UNESP), na Faculdade de Ciências de Bauru, no Departamento de Matemática. O grupo adota a utilização da História Oral como um recurso metodológico referencial de pesquisas em História da Educação Matemática, embora também incremente diferentes discussões sobre temas e abordagens teórico-metodológicas diversas no âmbito de suas pesquisas. Com base em seus estudos, o grupo vem elaborando um mapeamento histórico sobre a formação de professores de Matemática no Brasil, tomando a História Oral

\footnotetext{
${ }^{3}$ Quase todas as informações mencionadas sobre o GHOEM foram extraídas do Diretório do CNPq, do Currículo Lates de seus líderes e algumas publicações de membros do grupo.
} 
como possibilidade de contribuição para tais estudos e diversas intervenções em temas específicos da Educação Matemática, como concepções de professores de Matemática, identidade de grupos de pesquisa e estudos, referenciais teóricos para nortear análise de livros didáticos, formação de professores de Matemática, dentre outros.

Igualmente, em sua home page identificamos informações por meio das quais o coletivo do GHOEM destaca que seu interesse central é o estudo da cultura escolar e o papel da Educação Matemática nessa cultura. Assim, os temas abordados nos diversos trabalhos desenvolvidos no grupo incluem a formação de professores de Matemática, as variedades de narrativas características da história e memória, a História Oral, os manuais didáticos, as instituições de vários níveis e modalidades de ensino nos quais atuam professores de Matemática e dos quais a Matemática faz parte, a História da Educação Matemática, a análise de livros antigos e contemporâneos - didáticos ou não, formação e conservação de acervos etc.

Também na home page do GHOEM identificamos descrições evidenciando que, em decorrência da ampliação de seus descendentes ao longo de duas décadas, de 2002 a 2018 aproximadamente, o coletivo do GHOEM vem se mostrando multi-institucional pela diversidade de pesquisadores que compõem esse coletivo, contando com membros da UNESP e da FUNDEC (São Paulo), UFMS (Mato Grosso do Sul), IFMA (Maranhão), UFPB (Paraíba), UFMG e UFU (Minas Gerais), UFRN e UERN (Rio Grande do Norte), FURB (Santa Catarina), UFPR, UTFPR e UEM (Paraná), UNED (Bahia), UFP (Rio Grande do Sul), URCA (Ceará), entre atuais e egressos que atuam em outras universidades e instituições.

Em sua sede fixa na Faculdade de Ciências da UNESP de Bauru, há uma sala na qual está alocado o acervo de livros antigos do GHOEM, disponível a toda a comunidade de educadores matemáticos. O referido acervo conta com cerca de 1500 volumes, todos originais, produzidos desde o século XVII até o final do século XX, dentre os quais há vários exemplares - muitos deles raros - de manuais didáticos de Matemática; obras de referência em Matemática, Educação Matemática, Educação, Pedagogia, Sociologia e História; livros didáticos de outras áreas utilizados em antigas escolas de primeiras letras; textos relativos à legislação educacional brasileira, além de teses, dissertações e monografias em Educação e Educação Matemática.

Além dessas frentes de pesquisa, o GHOEM criou um subgrupo para desenvolver projetos de iniciação científica, o IC-GHOEM, cujos objetivos principais são: intensificar o oferecimento de estágios de iniciação científica aos estudantes de cursos de Licenciatura em 
Matemática das Universidades nas quais estão lotados os membros do grupo e promover o exercício de orientação de pesquisa aos "estudantes“ vinculados ao GHOEM que, como alunos de programas de mestrado e doutorado, serão futuros orientadores em cursos de graduação e programas de pós-graduação.

Nas linhas de pesquisa, são pensados, planejados e desenvolvidos projetos individuais $e$ coletivos do grupo, que respondem a princípios comuns que denotam as relações intracoletivas refletidas no estilo de pensamento do GHOEM. Nesse movimento, ocorre a formação de pesquisadores, diante de uma abrangência epistemológica e metodológica que procura respeitar e promover a diversidade, considerando como prioridade formar pesquisadores que, em sua descendência, possam formar novos grupos como egressos, e que, a partir de interações intra e intercoletivas experienciadas nessa formação, operem uma crítica metodológica como proposta de formação, tendo em vista a aposta em perspectivas não deterministas e não personalistas relativamente às pesquisas em História Oral; História; textos; campos científicos; flexibilidade em temas e abordagens; variedade de recursos (fontes e teorias de apoio); biografias (narrativas do eu - história personalista), Olhares Móveis: Jogos de Escalas, Centros e Periferias Estabelecidos; Outsiders, Teorização como Processo, teoria como caixa de ferramentas.

\section{Pesquisadores e estilos de pensamento do grupo}

Com base na epistemologia fleckiana, consideramos fundamental destacar nesta subseção os pesquisadores que representam os estilos de pensamento do grupo na institucionalização do coletivo de pensamento e práticas de pesquisa em História da Educação Matemática que são geradores de uma herança epistêmica por meio de seus descendentes. Neste artigo, destacaremos três pesquisadores, conforme mencionaremos a seguir.

O pesquisador Antônio Vicente Marafioti Garnica, que, no campo da Educação Matemática, representa um dos pilares dessa área de conhecimento (a raiz dessa árvore), com pesquisas que desaguam na formação de professores de Matemática, História Oral, História da Educação Matemática, Narrativas e Metodologia de Pesquisa. Destacamos que seu pensamento acerca da formação de professores ativa-se em direção às investigações historiográficas, com a adoção de fontes como livro didático, legislação, biografia, entre outros. Na História Oral e Educação Matemática, investe no desenvolvimento de referencial teórico que sustenta o uso da História Oral como recurso metodológico para as investigações em Educação Matemática, além 
de estabelecer reflexões teóricas para pensar nessa maneira de escrever a História como uma possível metodologia de pesquisa para a formação de pesquisadores.

Descendente de Garnica, em termos acadêmicos, a pesquisadora Ivete Maria Baraldi egressa de doutorado e orientada por ele, é se ergueu a partir de sua raiz formativa, alimentada no solo do GHOEM, atua no Departamento de Matemática - Faculdade de Ciências da UNESP de Bauru e orienta nos Programas de Pós-Graduação em Educação Matemática (UNESP - Rio Claro) e Educação para Ciências (UNESP - Bauru). Atualmente, desenvolve uma pesquisa sobre narrativas de professores, com vistas às possibilidades para estudos na História da Educação (Matemática) Brasileira e na formação de professores de Matemática em uma perspectiva inclusiva. Sua intenção é elaborar compreensões acerca da formação do professor de Matemática da escola básica e a necessidade da formação continuada para uma educação inclusiva, constituindo tramas da formação de professores de Matemática de uma região específica do Brasil e numa determinada especificidade (educação inclusiva) e, quando possível e necessário, em uma perspectiva histórica, a fim de corroborar as pesquisas já desenvolvidas pelos demais membros do GHOEM, bem como efetuar um estudo da arte acerca das pesquisas em Educação Matemática inclusiva, discussões acerca das narrativas orais (História Oral) ou escritas (memorial de formação) como fontes para as pesquisas em História da Educação Matemática.

Nessa mesma ramificação genealógica e fortalecida pelas raízes já fincadas no solo acadêmico do campo da história da Educação Matemática, a professora Heloisa da Silva, também descendente de Garnica, fortalece o tronco do grupo nessa árvore do campo plantado incialmente por Garnica. Atualmente é docente do Departamento de Educação Matemática, IGCE/UNESP, Rio Claro, é a vice-líder do GHOEM e atua como orientadora no Programa PósGraduação em Educação Matemática, IGCE/UNESP, Rio Claro, e pesquisa sobre o tema História da Educação Matemática na Formação de Professores de Matemática, embora também atue em outras pesquisas que envolvem História Oral, Narrativas e Educação Matemática; Formação de Professores de Matemática. No momento, desenvolve projetos de pesquisa sobre mobilizações de narrativas na/para a formação inicial de professores de Matemática na linha de pesquisa História Oral, Narrativas e Formação de Professores. Como pesquisa e intervenção no interior do GHOEM, busca mobilizar fundamentos e recursos da História Oral em atividades estrategicamente elaboradas para a formação professores que ensinam Matemática. 
Um novo caule surgiu nesta árvore, sendo alimentado desde que apontado no verde em broto surgido nessa genealogia do GHOEM: a professora Luzia Aparecida de Souza. A pesquisadora é licenciada em Matemática, Mestrado e Doutorado pela UNESP e egressa do GHOEM, exercendo atualmente função de coordenadora do Grupo História da Educação Matemática em Pesquisa e membro do Grupo de História Oral e Educação Matemática GHOEM. Atua como docente no Programa de Pós Graduação em Educação Matemática da UFMS (Campo Grande) e desenvolve pesquisas nesse campo, sobre temas como História da Educação Matemática, Narrativas e História Oral. A referida pesquisadora é um dos ramos novos da árvore genealógica de Garnica que, com outro pendões verdosamente amadurecendo, têm ampliado a copa da árvore com novos ramos ligados ao tronco e à raiz, conforme a metáfora de Michel Serres (2008) ao tratar do Formato-Pai e da Ciência Filha, em suas discussões epistemológicas sobre a formação dos pensamentos na Ciência

Conforme mencionamos ao longo deste artigo, reiteramos a base das presentes considerações ancorada nos parâmetros adotados para a construção das genealogias dos grupos como origem, da fundamentação teórica do grupo, área de pesquisa, produção científica, conexões epistemológicas e metodológicas, desmembramentos e ramificações em outras regiões do país a partir da formação pós-graduada, bases epistemológicas e metodológicas que forneceram a seus descendentes e a possibilidade de ampliar as matrizes teórico-metodológicas adquiridas na formação pós-graduada, bem como para bifurcar suas linhas de pesquisa e reinventar-se como grupo e como pesquisadores. A investigação apontou indício de uma formação para a pesquisa, para o ensino e para a gestão, de modo indissociável, pois em suas atividades acadêmicas os egressos do GHOEM têm demonstrado competências e habilidades para assumir posições empreendedoras no fortalecimento de seus campos de pesquisa, o que nos leva a pressupor que tal formação cria possibilidades para tal.

Apresentamos, a seguir, um mapa de localização dos descendentes do grupo e, em seguida, mostramos uma primeira versão da árvore genealógica do grupo (Figuras 05 e 06). 
Figura 05. Mapa de abrangência da formação de doutores e ação coletiva em pesquisa, realizada pelo GHOEM até fevereiro de 2018.

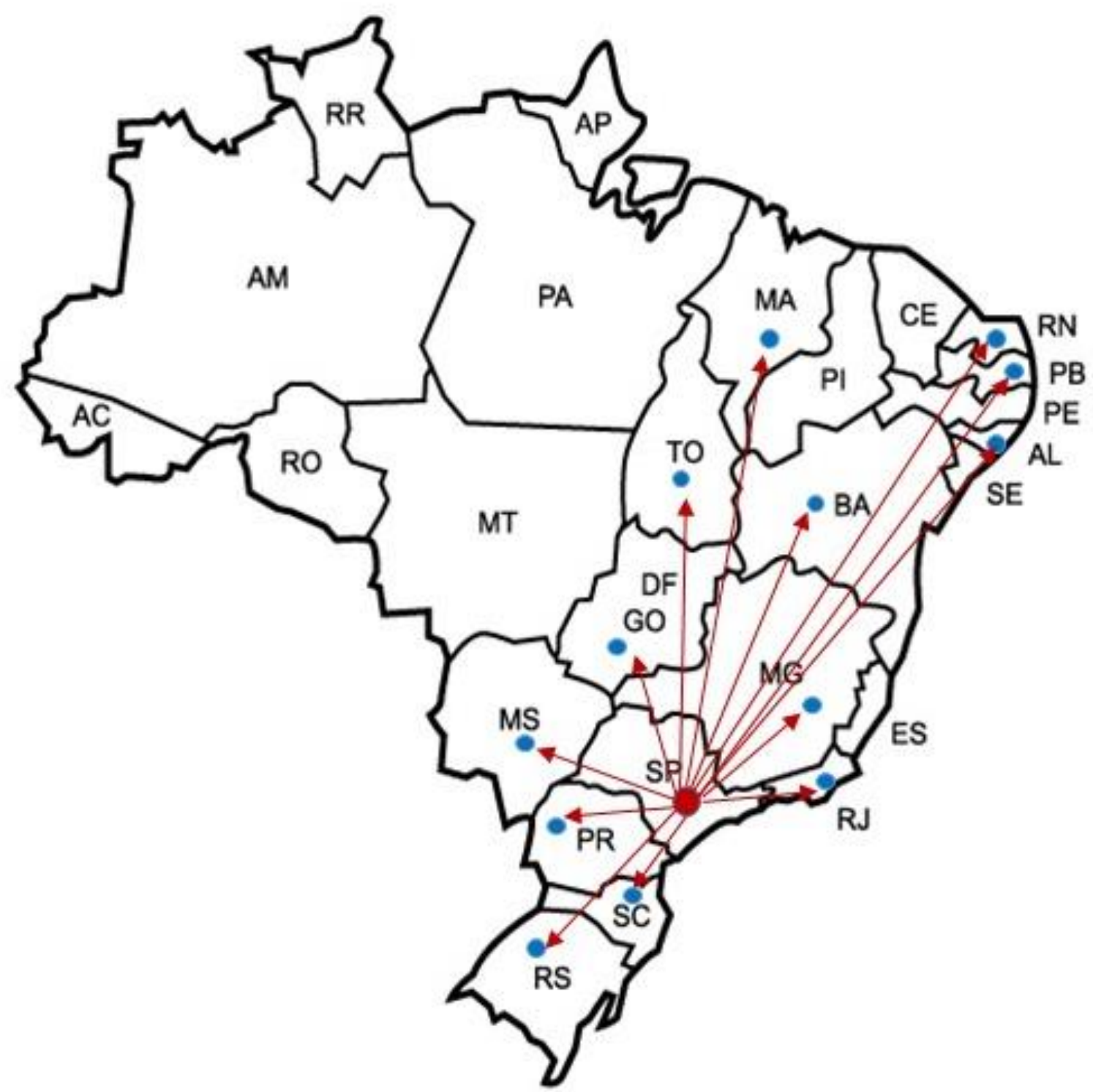

Fonte: Elaboração dos pesquisadores a partir dos documentos da Plataforma Lattes e Diretório dos Grupos do CNPq. 
Figura 06. Fluxo genealógico da formação de doutores e atuação coletiva em pesquisa, em conexão com o GHOEM até fevereiro de 2018.

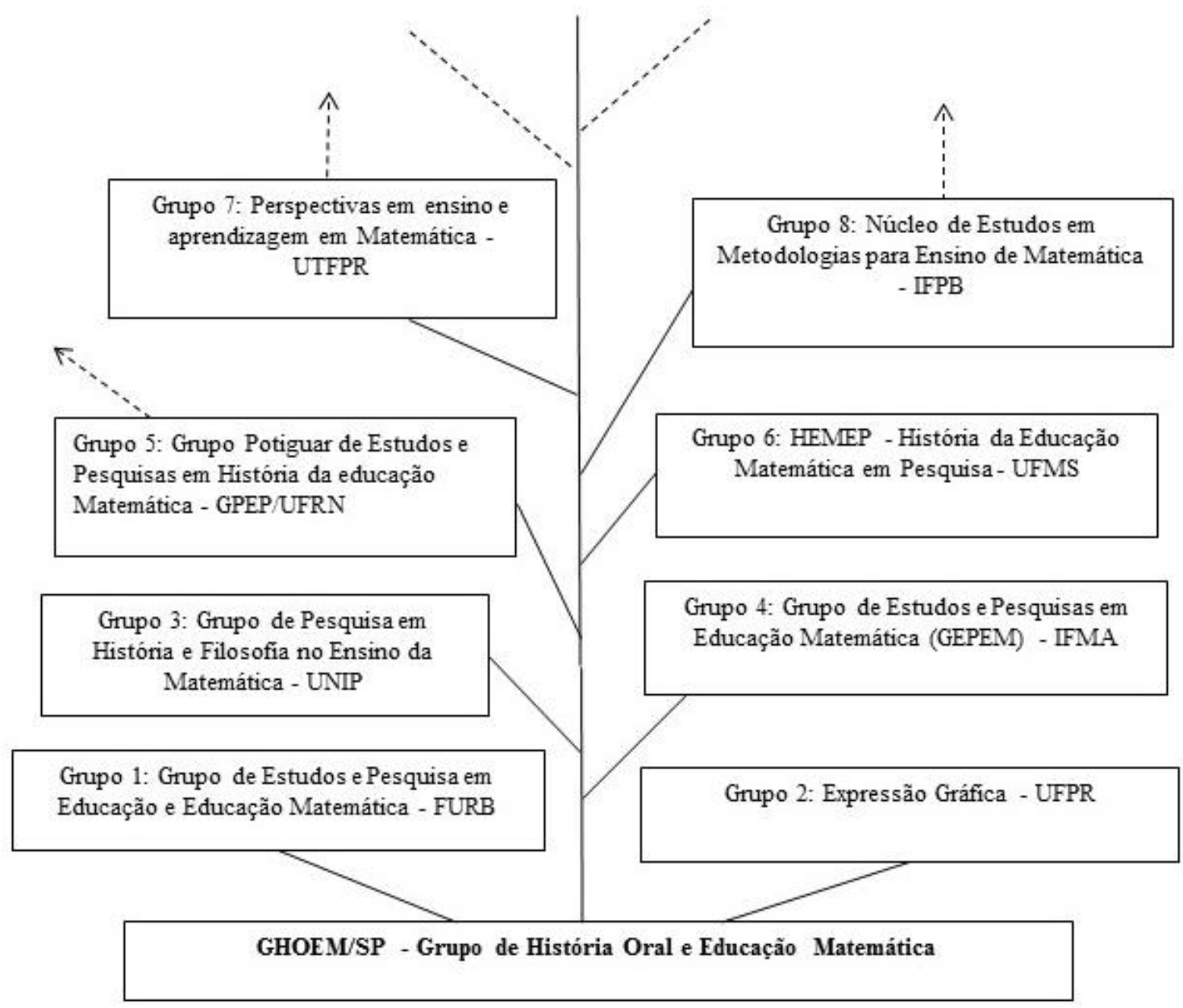

Fonte: Elaboração dos pesquisadores a partir dos documentos da Plataforma Lattes e Diretório dos Grupos do CNPq até fevereiro de 2018.

O site do GHOEM entrou em funcionamento no ano de 2004 e em 2007 foi criado um site específico para a divulgação do catálogo de todo o acervo do GHOEM (IC GHOEM). Para o pesquisador interessado, é possível encontrar mais informações sobre as atividades do grupo nos seguintes endereços eletrônicos: http://www2.fc.unesp.br/ghoem/ ou www.ghoem.org.

\section{Considerações Finais}

Conforme mencionamos ao longo das seções deste artigo, nossa intenção foi caracterizar o perfil de três grupos de pesquisa em História da Educação Matemática do Brasil, a partir do levantamento e da organização das informações levantadas no Diretório do CNPq e no Currículo Lattes dos pesquisadores, com enfoque na origem e na fundamentação teórico-metodológica 
adotada e praticada nos grupos com vistas a identificar implicações na produção científica de seus membros nesse campo de pesquisa, bem como acerca de suas conexões epistemológicas, metodológicas e ramificações em outras regiões do país, a partir da formação pós-graduada concretizada nas várias instituições de ensino superior onde estão sediados os grupos.

O foco da nossa investigação centrou-se nos pesquisadores que atuam no campo da História da Educação Matemática, almejando identificar, compreender e apresentar fluxos de ramificação dos fundamentos adotados nos grupos investigados que de fato contribuíram para a consolidação da pesquisa nesse campo de conhecimento. Assim, o levantamento preliminar realizado no Diretório do dos Grupos de Pesquisa do $\mathrm{CNPq}$ nos possibilitou avançar na compreensão sobre a criação e consolidação de grupos de pesquisas oriundos da formação de doutores participantes de grupos como o GHEMAT/UNIFESP, o GHOEM/UNESP (Rio Claro e Bauru) e o HIFEM (UNICAMP). Além disso, pôde-se asseverar que esses grupos forneceram as bases epistemológicas e metodológicas para que seus descendentes pudessem ampliar as matrizes teórico-metodológicas adquiridas na formação pós-graduada, bem como para dar continuidade ou bifurcar suas linhas teóricas e reinventar-se como pesquisadores.

Salientamos que os resultados obtidos na pesquisa demonstram o avanço na produção de uma epistemologia sobre as pesquisas em História da Educação Matemática, em uma ramificação potencializada nos grupos de pesquisa desse campo no Brasil. Do mesmo modo, a pesquisa apontou a existência de uma produção em crescimento significativo nessa área, que é estimulada por vários Programas de Pós-Graduação em Educação, Educação Matemática, Ensino de Ciências e Matemática, mas que precisam de maior sistematização e análise de informações a esse respeito, bem como da criação de um espaço ampliado de disseminação e interação profissional para contribuir com a formação dos professores de Matemática e dos pesquisadores em História da Educação Matemática, em seu processo formativo.

Percebemos, ainda, que a organização das informações levantadas no estudo foram de extrema importância para compreendermos como estão configurados geográfica e epistemologicamente os grupos de pesquisa do Brasil e suas inserções na formação de pesquisadores em História da Educação Matemática. Nesse sentido, as informações obtidas no Diretório dos Grupos do CNPq e no Currículo Lattes dos pesquisadores foram extremamente relevantes como ponto de partida para que empreendêssemos um estudo mais ampliado acerca da genealogia dos grupos pesquisados, tomando como referência uma organização detalhada da 
origem, fundamentação e produção científica de cada grupo, na área de pesquisa e também suas conexões epistemológicas, metodológicas e ramificações em outras regiões do país, a partir da formação pós-graduação concretizada em várias das instituições de ensino superior onde estão sediados os grupos.

Os resultados da pesquisa também destacaram o avanço dos estudos e pesquisas em direção a uma produção epistemológica sobre a História da Educação Matemática em suas multiplicidades teórico-metodológicas para melhor produzir historiografias de acordo com os temas e objetivos, implicando, desta feita, ramificações multiplicativas em outras regiões do Brasil, a enfatizar redes de conexão e os fluxos genealógicos de cada um dos três grupos investigados.

É possível, portanto, admitir que as atividades vivenciadas nos grupos de pesquisa são norteadoras da constituição de um estilo de pensamento no exercício formativo dos pesquisadores, de maneira a denotar a gênese dessa formação, ou seja, o DNA da célula geradora de uma epistemologia de grupo, tal como Fleck denomina - gestaltsehen - ou ver formativo. Nesse sentido, o pensamento de Fleck, tomado como referencial para a interpretação das práticas formativas dos grupos de pesquisa investigados, possibilitou-nos compreender as relações inter e intracoletivas que alimentaram o processo de instituição e institucionalização do coletivo de pensamento sobre a pesquisa em História da Educação Matemática em cada grupo e nas relações entre grupos, por meio de interações diversas como leituras e discussões em geral, eventos, palestras, oficinas, cursos e seminários, e outras ações que estabeleceram estilos de pensamento nessas comunidades, como também suas ramificações e disseminações em quase todas as regiões do Brasil.

Diante do que foi exposto, é possível afiançar que:

- Os exercícios de preparação e práticas em pesquisa estabelecidos nos grupos de História da Educação Matemática possibilitaram que os participantes se apropriassem dos estilos de pensamento no treinamento formativo em cada grupo;

- O pensamento de Fleck pode ser tomado como referencial para reflexão sobre o processo de formação das comunidades de pesquisa em História da Educação Matemática ou áreas afins;

- O processo de criação de grupos de pesquisa em história da Educação Matemática reflete exercícios do coletivo de pensamento e produzem estilos de pensamento que implicam 
nos modos de pensar e agir sobre a produção de conhecimento nesse campo de pesquisa, na formação do pesquisador e na produção de ideias, assim como na disseminação de um estilo de pensamento em outras comunidades investigativas do Brasil.

Além disso, verificamos que, após a incorporação dos descendentes desses grupos em outras comunidades investigativas, são experimentados novos desmembramentos epistemológicos, hibridismos e ramificações que ocorrem por meio de um processo de agenciamento de repertórios adquiridos na formação em pesquisa nos grupos, à qual recorrem os descendentes após sua formação pós-graduada. Há de se considerar que muitos deles migram para outras regiões do país a partir dessa formação, levando consigo os estilos de pensamento do coletivo (grupos) e os gestaltsehen (ver formativo e as bases epistemológicas e metodológicas) que forneceram a seus descendentes. Isto denota uma possibilidade de ampliar as matrizes teórico-metodológicas adquiridas na formação pós-graduada, bem como para bifurcar suas linhas de pesquisa e reinventar-se como grupo e como pesquisadores.

É importante também destacar que a organização das informações levantadas no Diretório do CNPq serviu como ponto de partida para empreendermos os modos como os grupos de pesquisa em História da Educação Matemática do Brasil estavam organizados em torno nos temas, dos objetos de estudo, fundamentos epistemológicos, princípios e métodos de pesquisa nesse campo, caracterizando, assim, sua origem, fundamentação e produção científica, bem como suas conexões epistemológicas, metodológicas e ramificações em outras regiões do país, a partir da formação pós-graduação concretizada em várias das instituições de ensino superior onde estão sediados os grupos.

Uma reflexão importante a esse respeito nos mostrou que os pesquisadores desse campo poderiam refletir sobremaneira sobre a necessidade de incorporar as matrizes teóricometodológicas de seus grupos durante seu processo formativo e procurar cotidianamente inserir todas as informações do grupo no Diretório do CNPq, sempre que possível, para que todos tenham uma imagem ou espelho que reflita de fato o gestaltsehen de cada grupo, seu estilo e coletivo de pensamento, para que assim se torne possível estabelecer linhas divisórias entre o que cada grupo faz, o que os diferencia e o que os aproxima.

Nessa senda, mencionamos que a criação de novos grupos de pesquisa oriundos da formação de mestres e doutores participantes de grupos como o GHEMAT, o GHOEM e o HIFEM, dentre outros que forneceram as bases epistemológicas e metodológicas para que seus 
descendentes pudessem ampliar as matrizes teórico-metodológicas adquiridas na formação pósgraduada, bem como bifurcar suas linhas teóricas e reinventar-se como pesquisadores, possibilitou a autonomia, a reinvenção epistemológica e a hibridação, mas não eliminou a relação de ligação matricial gerada em cada Grupo-Pai que formou seus descendentes.

\section{Referências}

Archassal, P. V. (2000). L’ABCdaire de La Généalogie. Paris: Flammarion.

Bombassaro, L. C. (1992). As fronteiras da epistemologia: como se produz o conhecimento. 3. ed. Petrópolis: Vozes.

CNPq. Diretório dos Grupos de Pesquisa (2018). www. cnpq.br. Acesso em: 25 fev. 2018.

Condé, Mauro Lúcio Leitão (Org.) (2012). Ludwik Fleck. Estilos de pensamento na ciência. Belo Horizonte: Fino Trato (Coleção Scientia).

Fleck, L. (2010) Gênese e desenvolvimento de um fato científico. Belo Horizonte: Ed. Fabrefactum (Coleção Ciência, Tecnologia e Sociedade).

Fleck, L. (1986). La génesis y el desarrollo de un hecho científico. Madrid: Alianza Editorial.

Giedymin J. (1986). Polish philosophy in the inter-war period and Ludwik Fleck's theory of thought-styles and thought-collectives. In: Robert Sonné Cohen and Thomas Schnelle (eds). Cognition and fact: Materials on Ludwik Fleck, 179-215. Dordrecht/Holland: D. Reidel Publishing Company.

Maia, C. A. (2015). História, Ciência e Linguagem: O dilema relativismo-realismo. Rio de Janeiro: Mauad X.

Mathematics Genealogy Project. http://www.genealogy.math.ndsu.nodak.edu/index.php. Acesso em: 20 jul. 2013.

Mendes, I. A. (2019). Pesquisas em História da Matemática no Brasil: flashes e imagens das produções em três décadas. Anais. XIII Seminário Nacional de História da Matemática. Fortaleza: SBHMat.

Mendes, I. A. (2018). Uma história das pesquisas em História da Matemática no Brasil: produções, disseminações e contribuições à Formação de Professores de Matemática. Projeto de Pesquisa CNPq. Belém: Universidade Federal do Pará.

Mendes, I. A. (2010). Cartografias da produção em História da Matemática no Brasil: um estudo centrado nas dissertações e teses defendidas entre 1990-2010. Projeto de Pesquisa. Natal: UFRN.

Mendes, I. A. (2012). Historia Social de la Educación Matemática en Iberoamérica: pesquisa em História da Matemática na pós-graduação brasileira e suas dimensões epistemológica, sociológica e pedagógica. Uniõn. Revista Iberoamericana de Educación Matemática, n. 30, jun. 
Mendes, I. A.; Silva, C. A. F. (2015). História da educação matemática brasileira: entre genealogias e coletivos de pensamento. Revista de História da Educação Matemática HISTEMAT, ano 1, n. 1. p. 89-103.

Mendes, I. A.; Silva, C. A. F. (2018). Pesquisa en historia de la matemática. Geneaolgías, conexiones y difusiones: el ejemplo del grupo GHEMAT. Revista Paradigma 39, n. extra. jun. 2018, p. 1-30.

Serres, M.(2008). Ramos. Rio de Janeiro: Bertrand Brasil. 